\title{
'Gestão Adaptativa': uma Proposta para o Gerenciamento de Redes de Inovação
}

\author{
Maria Angela Campelo de Melo \\ Marcia Cristina Esteves Agostinho
}

\section{ResUMO}

Este artigo propõe a 'Gestão Adaptativa' como abordagem para o gerenciamento de redes de inovação. Construída sobre duas perspectivas conceituais relacionadas - a Abordagem Sociotécnica e a Teoria da Complexidade - e integrando questões de planejamento e de gestão, a Gestão Adaptativa é proposta de forma a conferir maior adaptabilidade às organizações. Inicialmente, é apresentada a estrutura dessa metodologia em termos de seus princípios básicos e de um conjunto de ações de planejamento e gestão, que a compõem. Em seguida, desenvolve-se uma aplicação da metodologia como instrumento de análise de dois casos de redes de inovação e é discutida sua utilidade para o gerenciamento em tais ambientes organizacionais. Finalmente, apresentam-se os elementos que indicam vantagens da 'Gestão Adaptativa' em comparação às abordagens tradicionais, por contribuírem para acelerar o processo de aprendizado coletivo e estimular a geração de vínculos comunitários em redes de inovação.

Palavras-chave: redes de inovação; gestão adaptativa; administração complexa.

\begin{abstract}
This paper proposes 'Adaptive Management' as an approach to manage innovation networks. Built upon two related conceptual perspectives - the Sociotechnical Approach and the Theory of Complexity -, Adaptive Management confers greater adaptability to organizations by integrating planning and managing issues. Initially, the structure of this methodology is presented, in terms of basic principles and a set of planning and managing actions. Then, the methodology is used as a framework for analysis of two innovative networks cases, and its usefulness to the management of such organizational sets is discussed. Finally, elements that suggest advantages of 'Adaptive Management' in comparison to conventional managerial approaches are presented. Such elements contribute for speeding the collective learning process and stimulating the generation of community ties in innovation networks.
\end{abstract}

Key words: innovation networks; adaptive management; complexity management. 


\section{INTRODUÇÃO}

Constata-se que, atualmente, parte considerável do esforço de inovação se dá por meio de redes interorganizacionais. Até poucas décadas, uma solução considerada apropriada para suprir a insuficiência interna de conhecimento das organizações, aprimorar a capacitação para pesquisa, expandir a capacidade de produção e desenvolver a inovação eram as parcerias estratégicas. No entanto, conforme o ambiente econômico e tecnológico se torna mais complexo, a mera cooperação motivada por interesses comuns mostra-se impotente para lidar com as novas demandas da sociedade, porquanto, mais do que compor uma 'coletividade', se requer das organizações envolvidas em processo de inovação que constituam 'comunidade'. Para isso, é necessário que elas compartilhem significados, além de interesses (Lash, 1994). Entram em cena, então, as redes de inovação interorganizacionais, que propiciam a formação e consolidação dos vínculos comunitários.

Essas redes, diferentemente das convencionais parcerias estratégicas (Henderson, 1990), caracterizam-se pela percepção, por seus integrantes, de uma identidade compartilhada, que se reflete em postura de abertura e comunicação, propiciando a intensificação do fluxo de conhecimento e da geração de idéias. Vários são os fatores que podem levar um grupo de organizações a se tornar não apenas coletividade de parceiros, mas uma rede de inovação. Dentre esses fatores, merece destaque a forma de gerenciamento.

Este trabalho visa propor a 'Gestão Adaptativa' como abordagem apropriada ao gerenciamento de redes de inovação. Tal enfoque, que tem entre os seus propósitos conferir maior adaptabilidade às organizações, integra a questão do planejamento com a gestão de atividades e de pessoas. Para isso recorre às metodologias de 'Planejamento Inovador' (Melo, 1991) e de 'Administração Complexa' (Agostinho, 2003a).

Como resultado deste trabalho, pretende-se consolidar a proposta da Gestão Adaptativa, discutindo-se as vantagens de sua utilização em relação aos mecanismos de gerenciamento convencionais. Considerando os condicionantes do uso dessa abordagem, é apresentada uma proposta para sua implantação no gerenciamento de redes de inovação.

Este estudo compõe o projeto 'Planejamento e Organização de Sistemas Adaptativos: uma perspectiva interorganizacional', patrocinado pelo Ministério 
de Educação e Cultura do Brasil, por intermédio da Coordenação de Aperfeiçoamento de Pessoal de Nível Superior-CAPES.

\section{Gerenciamento de Redes}

A partir da constatação, que começou a se consolidar nas décadas finais do século XX, das vantagens inerentes às redes organizacionais, o gerenciamento dessas redes tornou-se um foco de interesse não apenas para as organizações que buscam uma atuação mais efetiva no complexo ambiente atual como também para a academia. A mudança de foco, requerida para maior adaptabilidade das organizações em contextos com alto grau de complexidade, passando da organização para seu domínio organizacional (Trist, 1976), tem continuamente aumentado o interesse em temas ligados a esse gerenciamento, variando do estudo da Administração de Cadeias de Suprimento (Lee, 2004) às pesquisas sobre alianças estratégicas (Das \& Teng, 2001; Googins \& Rochlin, 2000) e transformando a Governança de Redes no tema focal de eventos como a International Conference on Democratic Network Governance, realizada em outubro de 2004, em Copenhagen.

Uma definição de Governança de Redes é proposta por Jones, Hesterly, e Borgatti (1997, p. 911-945):

The terms "network organization" (Miles \& Snow, 1986), "networks forms of organization” (Powell, 1990), “interfirm networks”, “organization networks" (Uzzi, 1996, 1997), “flexible specialization” (Piore \& Sabel, 1984), and "quasi-firms" (Eccles, 1981) have been used frequently and somewhat metaphorically to refer to interfirm coordination that is characterized by organic or informal social systems, in contrast to bureaucratic structures within firms and formal contractual relationships between them (Gerlach, 1992, p. 64; Nohria, 1992). We call this form of interfirm coordination network governance $e^{(1)}$. Network governance constitutes a "distinct form of coordinating economic activity” (Powell, 1990, p. 301) which contrasts (and competes) with markets and hierarchies.

Argumentando ser necessário enfatizar a dinâmica dos sistemas humanos para produzir uma ordem emergente, buscando a adaptabilidade na ação, Smith e Stacey (1997, p. 92) preconizam a adoção de abordagens de formação de redes informais. Esses autores assim concluem:

The general conclusion is that a richer understanding of governance is to be reached by taking a dynamic, nonlinear view of human organizations. 
The dynamics are generated by the interplay between cooperation and competition, by nurturing forms of leadership and personal intervention and working with conflict and tension, and by informal systems working against formal ones.

A abordagem aqui proposta insere-se nessa perspectiva, visando contribuir para o aprimoramento da dinâmica de inter-relacionamento das organizações, com o objetivo de estabelecer ambiente propício à inovação.

\section{Gestão Adaptativa: uma Abordagem Gerencial}

A Gestão Adaptativa é uma abordagem gerencial desenvolvida para dotar os sistemas organizacionais com maior grau de adaptabilidade, buscando oferecer meios para aumentar a velocidade de resposta às pressões ambientais e melhorar a qualidade dessa resposta. Para isso propõe-se que tanto o planejamento quanto a gestão de pessoas e de processos sejam conduzidos segundo uma mesma lógica, de acordo com princípios comuns, para assegurar a coerência do empreendimento e, conseqüentemente, seu bom desempenho. Com esse objetivo a Gestão Adaptativa integra duas metodologias anteriormente propostas, isoladamente, pelas autoras deste trabalho: o Planejamento Inovador (Melo, 1991) e a Administração Complexa (Agostinho, 2003a). Essas metodologias têm suas origens epistemológicas na teoria de sistemas e propõem métodos de ação fortemente influenciados pelas experiências da Escola Sociotécnica. A Administração Complexa, em particular, inclui ainda os resultados de recentes pesquisas sobre sistemas complexos adaptativos.

O conceito de Planejamento Inovador foi introduzido para caracterizar os métodos, processos e estratégias de planejamento apropriados a uma organização que busca a inovação tecnológica e, necessariamente, seu dual, a inovação social, visando favorecer atitudes e posturas dos membros da organização propícias ao processo de inovação. Essa metodologia de planejamento foi concebida para constituir uma base para a inovação socioecológica, respeitando as inter-relações do ecossistema interorganizacional. Desenvolve-se por meio de uma postura de aprendizado-ação, propiciando a identificação de nódulos de inovação que possibilitam a formação de redes de ação inovadoras, no domínio interorganizacional. Sendo metodologia de planejamento adaptativo, atua no nível normativo e enfatiza a flexibilidade, a participação, o aprendizado e a acomodação ativa. Uma caracterização mais detalhada do Planejamento Inovador pode ser encontrada em Melo (2003). 
AAdministração Complexa é uma metodologia gerencial oriunda da Ciência da Complexidade, que entende a organização como sistema complexo capaz de aprender e adaptar-se, a partir de pressões ambientais. Tal compreensão permite que se tire proveito da capacidade de auto-organização natural desses sistemas. O foco da ação gerencial, segundo essa abordagem, concentra-se na geração e manutenção de condições propícias à autonomia, cooperação, agregação e auto-organização - que representam os processos-chave para a promoção da capacidade adaptativa de uma organização. A Administração Complexa é apresentada de forma completa em Agostinho (2003a, 2003b).

A Gestão Adaptativa, portanto, atualiza a contribuição sociotécnica, ao adotar a perspectiva da Ciência da Complexidade. Assim, alia à busca da otimização conjunta dos sistemas social e técnico elementos que contribuem para uma compreensão mais profunda da dinâmica sistêmica. As duas metodologias que a integram foram desenvolvidas de modo a aplicar-se a qualquer esfera organizacional, de equipes de trabalho até grupos de organizações. A integração dessas metodologias, aqui efetivada, é também realizada com vistas a ser viável para qualquer dessas esferas. Neste artigo, a abordagem é particularizada para a situação específica das redes de inovação interorganizacionais. Para isso utilizamse estudos de caso realizados no Departamento de Engenharia Industrial da Pontifícia Universidade do Rio de Janeiro-DEI/PUC-Rio, junto a redes de organizações e instituições que encaram o desafio de desenvolver projetos sob incerteza.

A Gestão Adaptativa é regida por princípios explicitados em seguida.

\section{Questionamento Normativo}

A discussão dos valores, com a identificação daqueles que são compartilhados, serve de base para o estabelecimento das direções comuns, a serem adotadas pelas diversas partes que se envolvem no processo inovador, lançando-se, assim, os fundamentos para a construção de uma comunidade. Visa-se estabelecer uma ordem negociada (Strauss, 1963), configurada em padrão de autoridade compartilhada. Essa ordem, por poder ser renegociada a cada momento, é, necessariamente, de natureza dinâmica ou, como diria Bauman (2001, p. 19), constitui "um acordo que precisa ser periodicamente renovado".

\section{Auto-organização}

A auto-organização ocorre quando um padrão de organização (estrutura ou comportamento) emerge das ações das partes do sistema, em vez de ser imposta por uma parte central dominante. (Agostinho, 2001). Este princípio promove a autodeterminação, englobando e transcendendo os princípios básicos do projeto 
sociotécnico de auto-regulação e autonomia e liberdade de ação, identificados por Trist (1981), pelos quais a iniciativa de cada membro é incentivada, em contraposição ao mero seguimento de regras prescritas.

\section{Ação Reflexiva e Adaptação}

O planejamento é percebido como processo de aprendizado participativo, que se realiza por meio de ação reflexiva. Recomenda-se uma postura de pesquisaação, a fim de dotar a organização com a flexibilidade requerida para atuar em ambiente complexo e incerto, possibilitando a constante avaliação de redefinição de trajetórias e objetivos (Melo, 1977). Preconiza-se uma adaptação ativa, pela qual a organização busca influenciar o comportamento do ambiente de modo que lhe seja favorável, e não apenas moldar-se a esse ambiente. Procura-se introduzir mudanças em focos geradores de mudanças, ou nódulos transformadores que se constituem em pontos de 'alavancagem', estabelecendo uma reação em cadeia que visa à transformação do sistema (Melo, 1985). Com isso, ocorrem 'eventos determinantes', que condicionam a seleção dos próximos estágios a serem atingidos. A evolução deve ocorrer por uma combinação de morfostase com morfogênese (Melo, 1985), simultaneamente adaptando as condições de equilíbrio e promovendo transformações essenciais ao sistema.

\section{Cooperação e Agregação}

Embora autônomos, os membros de uma organização são interdependentes. (Agostinho, 2001; Melo, 1977). Por isso precisam agregar-se, desenvolvendo atividades complementares. A agregação deve ser entendida, ao se considerar organizações, como a capacidade de atrair e reter indivíduos com interesses comuns ou compatíveis e competências relevantes (Agostinho, 2001). Pela agregação e cooperação, são consolidados vínculos comunitários, formando-se a identidade da organização, ou rede organizacional. A cooperação efetiva requer transparência nas decisões e ações, essenciais para o desenvolvimento da confiança, a qual só se conquista a partir da credibilidade. Esses constituem elementos essenciais para o desenvolvimento de uma comunidade.

\section{Redes de Inovação: um Desafio para o Gerenciamento}

Os últimos anos testemunharam crescente número de iniciativas de formação de redes interorganizacionais para fazer frente aos desafios contemporâneos de inovação tecnológica. Com isso busca-se compartilhar conhecimento e recursos, de modo a ampliar as capacidades isoladas de cada membro da rede, aumentando 
a eficiência coletiva. A contribuição para o aprimoramento do processo de inovação, advinda da formação de redes, é constatada e amplamente registrada no âmbito global, de modo que a constituição de redes de inovação é importante componente da estratégia competitiva industrial nos países avançados. A participação em arranjos de colaboração é considerada de grande relevância para que o processo de inovação ocorra de forma efetiva e, particularmente, para prover um meio mais rápido de desenvolver a capacitação tecnológica (Gonzalez Alvarez, 1997).

Diferentemente das redes locais de inovação, caracterizadas pela proximidade das organizações membros, cujas vantagens são amplamente discutidas e conhecidas (Porter, 1998), há, atualmente, crescente número de redes cujos membros são geograficamente dispersos, ou seja, de redes virtuais. Essa dispersão dificulta a formação e consolidação de vínculos comunitários, fundamentais para a emergência de cooperação duradoura.

Uma parcela considerável de redes é criada por decisão deliberada de um ator que, ao perceber a inviabilidade de assumir isoladamente a responsabilidade por uma inovação, arregimenta parceiros para seu desenvolvimento colaborativo. As redes assim formadas, conseqüentemente, costumam estar voltadas para um objetivo concreto, como o desenvolvimento de um produto específico. Nesse caso particular, configura-se a formação de uma multiorganização, de natureza ad hoc ou mais permanente, caracterizada pelo "desempenho de uma determinada tarefa (que pode ser contínua) por meio da interação entre indivíduos” (Stringer, 1967, p. 107). As multiorganizações constituem uma solução para situações em que os problemas são passíveis de delimitação, envolvendo órgãos autônomos com parcelas diferenciadas de responsabilidade (Melo \& Melo, 1985). Neste trabalho, a discussão está restrita a casos que apresentam características de multiorganizações.

No caso da multiorganização, a existência de ator que exerce a liderança assimetricamente e de objetivo concreto tende a facilitar o gerenciamento da rede. Essa situação pode induzir a adoção do referencial administrativo clássico, que separa o planejamento da execução, com as tarefas que irão produzir o objeto final prescritas e atribuídas aos demais atores, estabelecendo-se também mecanismos centrais de controle. Discordando de Christensen, Anthony e Roth (2004, p. 283), que afirmam que "a gerência é a única força capaz de coordenar essas interdependências", a Gestão Adaptativa oferece nova abordagem que se baseia na capacidade de auto-organização dos sistemas de inovação e não mais na autoridade hierárquica de alguns poucos indivíduos. Esse novo enfoque parece ser capaz de melhor responder aos desafios impostos às organizações modernas, que estão expostas a um contexto turbulento, caracterizado por alto grau de incerteza, interdependência e complexidade (Emery \& Trist, 1965). 
As redes de inovação tendem a apresentar características-chave que dificultam seu gerenciamento da forma convencional. Elas surgem como resposta a demandas por inovação nesses ambientes turbulentos, em que a velocidade de geração de conhecimento e a necessidade de absorção desse conhecimento são muito altas. Isso requer que essas redes aumentem a velocidade de aprendizado - o que dificilmente é atingido por meio de estruturas de controle centralizado e simples divisão de tarefas.

A Gestão Adaptativa apresenta-se como alternativa para o planejamento e o gerenciamento de redes de inovação, focando, fundamentalmente, na velocidade de aprendizado coletivo e na criação de vínculos comunitários.

Complementando a apresentação, feita na seção anterior, da definição conceitual da Gestão Adaptativa, cabe ainda tratar das características desta metodologia em termos mais concretos, com a finalidade de facilitar sua compreensão. Para isso recorre-se à experiência de duas redes de inovação anteriormente estudadas no DEI/PUC-Rio: 'Rede de Turbinas a Gás' (Sheremetieff Jr., 2003) e 'Projeto ERJ 170' da Embraer (Freitas, 2000). Apesar de essas redes terem sido desenvolvidas segundo metodologias próprias, diferentes da Gestão Adaptativa, definidas pelos responsáveis por seu gerenciamento, sua descrição, feita a seguir, fornece situações reais cuja análise propicia o melhor entendimento dos elementos da abordagem proposta.

Na seção subseqüiente, a Gestão Adaptativa é utilizada como referencial para análise dessas redes. Cada etapa da metodologia de Gestão Adaptativa é então apresentada, sendo ilustrada com referência às condicionantes das redes estudadas. Embora não sendo exemplos de aplicação da metodologia, esses casos representam situações em que esse modelo constitui uma alternativa mais adequada para a gestão de redes de inovação do que as abordagens administrativas convencionais.

\section{Rede de Pesquisa e Desenvolvimento de Turbinas a Gás}

A criação da 'Rede de Pesquisa e Desenvolvimento de Turbinas a Gás' - RTG, em 2001, foi motivada pela crise energética enfrentada pelo país naquele ano. A iniciativa surgiu do 'Encontro sobre a Inserção de Tecnologias de Turbinas a Gás no Brasil', promovido por órgãos federais, como o Ministério de Ciência e Tecnologia, e pela Federação das Indústrias do Estado do Rio de Janeiro. (Sheremetieff Jr., 2003). Nesse encontro, detectou-se a necessidade de se desenvolver um esforço nacional de pesquisa e desenvolvimento, com o objetivo de deter a tecnologia de concepção, projeto, fabricação, montagem, ensaios, desenvolvimento, operação e manutenção de turbinas a gás. Tornou-se importante, então, reunir instituições de ensino superior, centros de pesquisa e indústria, 
formando uma rede que viabilizasse a realização desse objetivo - tarefa impossível para qualquer desses atores isoladamente.

A coordenação da RTG é exercida por um Coordenador Geral, especialista da área, que conta com o apoio da Financiadora de Estudos e Projetos - FINEP, órgão ligado ao Governo Federal.

De acordo com o cronograma de atividades, os integrantes da RTG serão convidados para a apresentação dos projetos apropriados a cada Fase do programa. Os projetos serão compatibilizados pelo Coordenador Geral, ouvidos os Coordenadores de Áreas, e submetidas à FINEP e, em última instância, ao Conselho Gestor do CT - ENERG. [...]. Aprovado um projeto, é de responsabilidade do gerente do projeto, que pode ser o próprio Coordenador de Área, a sua execução conforme o planejado e aprovado (Sheremetieff Jr., 2003, p. 116).

Considerando que a FINEP é a única fonte de recursos para as atividades da RTG, sua influência é preponderante sobre as decisões das outras instituições que compõem a rede. "A participação das instituições está vinculada diretamente ao fomento. Sem os recursos da FINEP, a participação das instituições deixa de existir" (Sheremetieff Jr., 2003, p. 122). Dessa forma, o papel dos componentes da rede é predominantemente de execução dos projetos. Tal função assemelha-se a de subcontratados, principalmente se for levado em conta que, em função das regras de financiamento adotadas, “...os participantes não dependem dos resultados do projeto” (Sheremetieff Jr., 2003, p. 122). As instituições recebem os recursos para execução de seus projetos, independentemente de seu desempenho final.

Devido a atrasos na liberação de verbas, até abril de 2003 as atividades da RTG não tinham sido efetivamente iniciadas. Mesmo assim, de acordo com sua estrutura de funcionamento, é possível afirmar que a RTG deverá funcionar, fundamentalmente, de forma virtual, estando a transferência de dados e informações baseada, quase exclusivamente, em tecnologia de informação. A dispersão geográfica é uma característica essencial dessa rede, pois, "por força da legislação, deverão participar representantes de todas as regiões do país" (Sheremetieff Jr., 2003, p. 122). No entanto, não parece existir um esforço para promover eventos presenciais, que permitam encontros face-a-face e o consequiente fortalecimento dos vínculos entre os participantes.

\section{Projeto ERJ 170 da Embraer}

O ‘Projeto ERJ 170’ da Embraer surgiu, em 1999, da necessidade de desenvolver uma nova aeronave que garantisse o faturamento da empresa nos anos seguintes. 
Para aproveitar uma oportunidade no mercado para aviões a jato de 70 a 100 lugares, era preciso enfrentar o desafio de concluir a fase de desenvolvimento e homologação do projeto em tempo recorde. Caso contrário, a 'janela de demanda' fechar-se-ia, pois os concorrentes já estavam com projetos em andamento para esse segmento (Freitas, 2000, p. 65). Entretanto, a capacidade da Embraer não era suficiente para garantir que o Projeto ERJ-170 atingisse as especificações exigidas nos prazos requeridos. De acordo com um engenheiro da Empresa, "com as instalações presentes, convênios com o CTA e mais o pessoal competente da Empresa, seria possível viabilizar tecnicamente a nova aeronave, porém o tempo despendido para a conclusão do projeto seria impraticável e inadequado" (Freitas, 2000, p. 67).

Visando, principalmente, solucionar o problema de capacidade, formou-se, então, uma rede de parceiros, reunindo 25 participantes, cada qual responsável pelo desenvolvimento de um conjunto de partes ou sistema do avião e pelas interfaces com os demais. A responsabilidade pelo gerenciamento das interfaces, compartilhada por todos os parceiros, tornou mais evidente a interdependência das atividades. Ao contrário de outros projetos anteriormente conduzidos na Embraer, neste caso o parceiro tinha autonomia para escolher a tecnologia a ser utilizada, conforme julgasse mais adequado e menos oneroso. Dessa forma, os riscos do projeto eram mais significativamente compartilhados.

A organização do trabalho foi caracterizada por equipes multidisciplinares, cujos membros pertencem às várias organizações parceiras, com ao menos um integrador da Embraer. Do nível mais operacional até a alta gerência, o nível de instrução mínimo era igual ao segundo grau completo. O grupo de trabalho participou, igualmente, do planejamento e da execução das atividades.

Essa nova forma de organização do trabalho, até então não experimentada pela Embraer, permitiu que a interação e integração entre os diversos grupos responsáveis por cada sistema ou estrutura do avião fossem mais eficientes. Assim, um engenheiro do sistema de controles de vôo deve interagir e compreender as interferências do seu sistema no grupo responsável pela fuselagem do avião, por exemplo (Freitas, 2000, p. 76).

Após decidirem conjuntamente as especificações básicas do avião, a fase de detalhamento era realizada por cada parceiro em seu país de origem. O trabalho passou a ser disperso geograficamente, sustentado pelas tecnologias de informação e comunicação disponíveis.

As características da rede de inovação criada para o ERJ 170 são resumidas como se segue. 
. Seleção baseada em competências. Os parceiros foram selecionados em função de seu potencial para gerar maiores ganhos para o projeto.

- Riscos compartilhados. Cada parceiro arcou com os gastos de desenvolvimento de seus sistemas.

. Dispersão geográfica. Embora os vários parceiros realizassem suas atividades nos locais de origem, inicialmente todos eles compartilharam um período de trabalho conjunto na sede da Embraer.

- Assimetria entre parceiros. Ainda que, nesse projeto, todas as especificações não fossem definidas pela Embraer e repassadas aos parceiros para que executassem suas tarefas, essa empresa mantinha uma posição dominante sobre as demais. A coordenação e o controle do projeto era nela centralizado, embora cada parceiro fosse responsável pelas decisões críticas relativas à realização das partes que lhe cabiam: gastos, escolhas de tecnologias, retrabalhos, gerenciamento de interfaces etc. Vale ressaltar que tal assimetria era relativa; só pode ser observada nesse arranjo específico, porquanto, fora dessa rede, em suas demais atividades, alguns parceiros eram maiores e mais poderosos que a Embraer. Convém mencionar que a rede em exame era formada por grandes empresas internacionais, como General Electric e Kawasaki.

Os casos aqui apresentados ofereceram as situações reais que, devidamente problematizadas, permitem que a abordagem proposta seja compreendida.

\section{Gestão Adaptativa em Redes de Inovação: uma Possibilidade}

Conforme mencionado, a Gestão Adaptativa foi construída a partir da combinação de duas metodologias propostas pelas autoras, com focos no planejamento e na gestão de organizações e de arranjos organizacionais em geral. Argumenta-se, aqui, que esta abordagem pode ser aplicada ao caso específico das redes de inovação, sendo benéfica no que diz respeito à aceleração do aprendizado coletivo e à criação de vínculos comunitários que favoreçam relações cooperativas. Não se pretende, contudo, provar objetivamente a superioridade dessa abordagem - uma vez que redes de organizações não são objetos cujas variáveis sejam passíveis de observação controlável.

Opta-se, aqui, por uma alternativa diferenciada de caracterização da metodologia, buscando-se não um exemplo ou simulação de aplicação, mas descrever cada um dos seus elementos por meio de sua utilização como base de análise das redes de inovação acima delineadas. Assim, cada etapa da metodologia de Gestão 
Adaptativa é discutida, tendo como referência os condicionantes dos casos estudados. A apreciação desses dois casos reais e distintos oferece espaço para reflexão sobre as variáveis relevantes para o gerenciamento de redes de inovação.

A metodologia de Gestão Adaptativa aplicada ao planejamento e gerenciamento de redes de inovação, em particular daquelas criadas deliberadamente para desenvolvimento de um produto, como as aqui descritas, pressupõe uma série de ações, que refletem os princípios da abordagem, anteriormente formulados. Ei-las.

\section{Ações de Planejamento}

Identificação de um 'agente reticulador' e de uma 'tarefa articuladora'. A função de negociar as relações entre os demais integrantes deve ser desempenhada por uma das organizações que integram a rede, identificada como um 'agente reticulador' (Burns, 1981). Nos casos apresentados, os agentes reticuladores são a Coordenação da RTG e a Embraer. A coerência da rede, contudo, não é conseguida apenas por meio da negociação das inter-relações. É importante a definição de uma 'tarefa articuladora' (Melo, 1977), projetada para permitir que os esforços de cada integrante da rede sejam direcionados para um objetivo concreto comum, o qual deve funcionar como princípio organizador. A partir de então, inicia-se um processo contínuo de atração de integrantes, com base em suas competências e em seu potencial de contribuição para a realização da tarefa articuladora. Somente atividades que podem gerar uma reflexão sobre os objetivos do conjunto e do papel de cada parte nesse conjunto têm condições de prover as ligações desejadas, fortalecendo a rede. Nos casos em estudo, como em qualquer multiorganização, o desenvolvimento do produto constitui essa tarefa articuladora.

. Estabelecimento de 'mínima especificação crítica' (Herbst, 1974) que oriente a ação dos diversos atores na rede. Com isso, define-se a organização geral da rede, com suas regras de funcionamento e seus mecanismos de comunicação e de monitoramento reflexivo. Para garantir a contínua articulação, é necessário estabelecer instrumentos articuladores, cuja natureza seja ligada à da tarefa articuladora (Melo, 1986). No caso do 'Projeto ERJ 170', as especificações básicas do avião foram estabelecidas conjuntamente pelos parceiros, cabendo a cada um o detalhamento de seu sistema. Já na RTG, os projetos serão compatibilizados pelo Coordenador Geral, ouvidos os Coordenadores de Área.

Estabelecimento de um contrato (ainda que tácito) que garanta a coresponsabilidade pelos resultados positivos ou negativos da rede. Os integrantes da rede devem compartilhar os riscos associados a decisões críticas, 
tais como gastos e escolhas tecnológicas, cada qual contribuindo com uma parcela dos recursos, incluindo materiais, na medida de sua capacidade. Para promover o senso de co-responsabilidade, é importante que as recompensas sejam vinculadas ao desempenho na realização da tarefa articuladora. No caso da Embraer, cada parceiro foi responsável pelas decisões relativas à realização das partes que lhe couberam. Na RTG, uma vez aprovado um projeto, o responsável por sua execução conforme o planejado é o Gerente do Projeto.

\section{Ações de Gerenciamento}

Legitimação da autonomia de cada componente da rede. Pretende-se, com isso, reduzir as chances de que a diferença de poder de influência entre cada organização-parceira venha a gerar constrangimentos para o processo decisório autônomo. Cabe ao agente reticulador a função de ativar a rede, em cada momento, mobilizando cada membro quando sua participação se fizer necessária (Melo, 1986). Em ambos os casos apresentados, há uma organização notadamente mais influente que as demais, que assumiu a função de agente reticulador. Apesar disso, a RTG e o Projeto ERJ 170 diferenciam-se na medida em que esse último garante a autonomia das organizações-parceiras, responsáveis pelas decisões críticas de suas atividades, até mesmo quanto à escolha tecnológica e gastos. Na RTG, as regras de funcionamento equiparam os componentes da rede a 'contratados', que devem obedecer às determinações do 'contratante'. É de se esperar que o Projeto ERJ 170 tenha maiores chances de obter resultados efetivos mais rapidamente, uma vez que conta com a capacidade de julgamento de inúmeros indivíduos em grande número de organizações, expostos aos mais diversos estímulos e desenvolvendo considerável variedade de respostas. A RTG, por outro lado, tem seu desempenho limitado pelo conhecimento e visão de alguns poucos indivíduos em posições de liderança. Considerando a turbulência que caracteriza os mercados em que essas redes atuam, a alternativa 'autônoma' adotada pelo Projeto ERJ 170 tende a produzir melhores desempenhos.

\section{. Garantia de que os mesmos indivíduos que representam as organizações-} parceiras participem tanto do planejamento quanto da execução das atividades, criando modelos coletivos, compartilhados. Desta forma, os indivíduos têm acesso à realidade presente e podem perceber sua dinâmica e seus desafios, bem como suas restrições. A criação de soluções inovadoras ocorre, então, a partir da problematização da situação concreta. Em relação a esta ação, tanto na RTG como no Projeto ERJ 170, cada membro é responsável pelo planejamento e execução de suas atividades, criando-se a oportunidade de agilizar o processo de aprendizado e de geração de soluções inovadoras. No 
entanto, na primeira, o Coordenador Geral centraliza as decisões sobre as interfaces dos projetos.

- Vinculação das avaliações de desempenho individuais e das equipes ao desempenho global, permitindo a reflexão sobre os efeitos das ações realizadas. Segundo a abordagem clássica, o desempenho sistêmico tende a ser considerado menos relevante do que a correta execução de uma tarefa ou de um projeto especificado detalhadamente. Esse é o caso da RTG, em que as instituições que fazem parte da rede não dependem de seus resultados. Seja qual for seu desempenho particular ou sua contribuição para o desempenho global, sua recompensa será a mesma. A perspectiva do Projeto ERJ 170, por outro lado, estimula a preocupação com a avaliação de desempenho em todos os níveis, já que as organizações-parceiras são co-responsáveis pelos riscos que assumem. Em primeiro lugar, elas realizam investimentos e, em segundo, a recompensa não está garantida a priori.

\section{- Estímulo ao uso intenso de meios de informação e comunicação para} que os diversos atores - considerados tanto no nível da organização quanto do indivíduo - monitorem mutuamente seus desempenhos. É importante criar espaços de convívio para que a reflexão acerca das ações e de seus resultados possa também ser feita em conjunto, possibilitando o aprendizado coletivo. Dessa forma, o desempenho torna-se transparente, permitindo a avaliação por cada membro e pelos pares. Se for verdade que, como defende Thorstein Veblen (in Bauman, 2001, p. 31), há um “instinto do trabalho bem feito" em cada pessoa, então o reconhecimento pode tornar-se, em si, uma das recompensas. Como afirma Dejours (1999, p. 55), “o reconhecimento é a forma específica da retribuição moral-simbólica dada ao ego, como compensação por sua contribuição à eficácia da organização do trabalho, isto é, pelo engajamento de sua subjetividade e inteligência". Dejours (1999, p. 55) ressalta ainda que o julgamento proferido pelos pares "confere qualitativamente ao ego o pertencimento ao coletivo ou à comunidade de pertença". Portanto, o monitoramento mútuo dos desempenhos, além de agilizar o aprendizado coletivo, promove a formação de vínculos comunitários, importantes para a manutenção de relações colaborativas. As informações a respeito da RTG não permitem afirmar que existam mecanismos para essa finalidade. No caso do Projeto ERJ 170, havia condições para que a avaliação mútua ocorresse, pois havia equipes multidisciplinares, com membros das organizações parceiras, com um integrador da Embraer. Isso permitiu a eficiente interação entre os grupos responsáveis por cada sistema.

- Favorecimento do encontro face-a-face, realizando eventos que criem oportunidades de contato, principalmente, entre aqueles que estão 
geograficamente dispersos. Isso promove uma visão do outro como aliado, estabelecendo um padrão de relacionamento calcado no compartilhamento, e não na troca, o que é fundamental para o fortalecimento de laços comunitários. Ademais, tais contatos entre 'diferentes' aumentam as chances de surgimento de inovações 'acidentais', a partir da propagação de idéias diversas. O caso do Projeto ERJ 170 ilustra como o encontro pode ser favorecido, ainda que a rede precise funcionar, durante grande parte do tempo, geograficamente dispersa. No momento em que foi estabelecido que as equipes interdisciplinares, formadas por membros das várias organizações-parceiras, definiriam, em conjunto e na sede da Embraer, as especificações do avião, gerou-se um evento determinante. A partir de então, as organizações-parceiras, por meio de seus representantes nas equipes de trabalho, poderiam reconhecer-se mutuamente, criando laços e construindo uma linguagem compartilhada. $\mathrm{O}$ processo de comunicação, iniciado em uma situação concreta, estende-se para as etapas posteriores, em que os integrantes da rede são dispersos para fazerem o detalhamento em seus locais de origem. Dessa forma, a intercomunicação e a geração de inovações podem ser mais efetivas do que poderia ser esperado no caso da RTG, em que a rede foi projetada para funcionar virtualmente desde o início.

\section{Conclusão}

Neste trabalho, introduz-se a metodologia de Gestão Adaptativa, propondo-a como apropriada ao gerenciamento de redes de inovação. Essa abordagem foi, aqui, utilizada como referencial para análise de redes de inovação com características de multiorganizações. A extensão dessa análise para redes de inovação de maior grau de complexidade constitui a próxima etapa para o aprimoramento da Gestão Adaptativa e sua validação para o gerenciamento de redes interorganizacionais.

A proposta foi estruturada em termos de princípios gerais e de um conjunto de ações de planejamento e gerenciamento. A partir da apreciação desses princípios e com base nos resultados da análise aqui realizada de duas redes de inovação, resumem-se, a seguir, elementos que sugerem a superioridade da adoção dessa abordagem em relação a mecanismos de gerenciamento convencionais.

Ao preconizar questionamento no nível normativo, auto-organização, ação reflexiva, adaptação, cooperação e agregação, a Gestão Adaptativa permite substituir vínculos frágeis, baseados em interesses locais eventuais, por outros mais fortes, enraizados na percepção de participação em uma comunidade. O aprendizado participativo, oriundo da ação reflexiva, facilita a adaptação ativa, 
promovendo a transformação que propicia a sobrevivência do sistema em ambiente competitivo.

As ações de planejamento e gerenciamento constituem o núcleo da abordagem, traduzindo operacionalmente seus princípios. Tais ações têm por finalidade orientar os tomadores de decisão no sentido de 'ativarem a rede', mantendo-a dinamicamente articulada, de modo a atingir efetivamente seus objetivos. Para isso devem ser projetadas de modo a direcionar os esforços dos integrantes para objetivos comuns, fazendo-os co-responsáveis pelos riscos e equilibrando influências. Reunindo planejamento e execução e estabelecendo mecanismos para o monitoramento mútuo de desempenhos - de forma congruente com os objetivos da rede, a Gestão Adaptativa estimula o aprendizado coletivo, além de favorecer a geração de vínculos comunitários. A abordagem apresenta-se, portanto, como alternativa gerencial que mobiliza o potencial sinérgico natural da rede, identificando os nódulos em que intervenções localizadas geram eventos determinantes, capazes de propagar mudanças sistêmicas.

Cabe destacar que a coerência dessas redes é dinâmica, sendo calcada em uma ordem negociada que se fundamenta em acordos continuamente renovados. Assim, criam-se e desenvolvem-se condições favoráveis para um ágil aprendizado coletivo e para a consolidação de vínculos comunitários mais duráveis.

\section{Artigo recebido em 20.09.2004. Aprovado em 15.12.2004.}

\section{Nota}

${ }^{1}$ Explicam os autores: "The term 'network governance is used rather than 'network organization' because many scholars in management define 'organization, either implicitly or explicitly, as a single entity. 'Governance' more accurately captures the process and approach to organization among firms that we discuss here."

\section{Referéncias Bibliográficas}

Agostinho, M. C. E. (2001).

A organização emergente: gerenciando o processo de auto-organização, Tese de Doutorado, Universidade Federal do Rio de Janeiro, Rio de Janeiro, RJ, Brasil.
Agostinho, M. C.E. (2003a, janeiro/julho). Administração complexa: revendo as bases científicas da administração. RAE Eletrônica, 2(1). Recuperado em 06 dezembro, 2004, de www.rae.com.br 
Agostinho, M. C. E. (2003b).

Complexidade e organizações: em busca da gestão autônoma. São Paulo: Editora Atlas.

Bauman, Z. (2001).

Comunidade: a busca por segurança no mundo atual. Rio de Janeiro: Jorge Zahar Editor.

Burns, T.F. (1981).

Planning networks and network agents: an approach to adaptive community governance. Tese de Doutorado, University of Pennsylvania, Filadélfia, Pensilvânia, EUA.

Christensen, C.,

Anthony, S., \&

Roth, E. (2004).

Seeing what's next: using the theories of innovation to predict industry change. Boston: Harvard Business School Press.

Das, T. K., \&

Teng B. S. (2001, March).

Trust, control, and risk in strategic alliances: an integrated framework. Organization Studies, 22(2), 251-284.

Dejours, C. (1999).

O fator humano. Rio de Janeiro: Fundação Getúlio Vargas.

Eccles, R. G. (1981, December).

The quasifirm in the construction industry. Journal of Economic Behavior and Organization, 2(4), 335-357.

Emery, F., \&

Trist, E. L. (1965, February).

The Causal Texture of organizational environments. Human Relations, 18(1), 21-32.
Freitas, J. M. H. (2000).

Um estudo da virtualidade empresarial: o caso do projeto ERJ170 da Embraer. Dissertação de Mestrado, Pontifícia Universidade Católica do Rio de Janeiro, Rio de Janeiro, RJ, Brasil.

Gerlach, M. L. (1992, March).

The Japanese corporate network: a blockmodel analysis. Administrative Science Quarterly, 37, 105-139.

Gonzalez Alvarez, M. D. (1977).

Processos de planejamento nos pólos tecnológicos - um enfoque adaptativo. Tese de Doutorado, Pontifícia Universidade Católica do Rio de Janeiro, Rio de Janeiro, RJ, Brasil.

Googins, B. K., \&

Rochlin, S. A. (2000, Spring).

Creating the partnership society: understanding the rhetoric and reality of cross-sectoral partnerships. Business and Society Review, 105(1), 127-144.

Herbst, P. G. (1974).

Socio-technical design. Londres: Tavistock Publications.

Henderson, J. C. (1990, Spring).

Plugging into strategic partnerships: the critical IS connection. Sloan Management Review, 31(3), 7-18.

Jones, C.,

Hesterly, W. S., \&

Borgatti, S. P. (1997, October).

A general theory of network governance: exchange conditions and social mechanisms. Academy of Management Review, 22(4), 911-945. 
Lash, S. (1994).

Reflexivity and its doubles: structure, aesthetics and community. In U. Beck, A. Giddens, \& S. Lash (Orgs.). Reflexive Modernization. Londres: Polity Press.

\section{Lee, H. L. (2004, October).}

The Triple-A Supply Chain. Harvard Business Review, 82(10), 102-113.

Melo, M. A. C. (1977).

Articulated incrementalism- a strategy for planning with special reference to the design of an information system as an articulative task. Tese de Doutorado, University of Pennsylvania, Filadélfia, Pensilvânia, EUA.

Melo, M. A. C. (1985).

A pesquisa-ação e o processo de planejamento: uma perspectiva de aprendizado. Anais do Encontro Nacional de Engenharia de Produção, Florianópolis, SC, Brasil, 5.

Melo, M. A. C. (1986).

A dimensão inter-organizacional do planejamento de C\&T: elementos para uma metodologia. Anais do Simpósio Nacional de Pesquisa de Administração em Ciência e Tecnologia, São Paulo, SP, Brasil, 11.

Melo, M. A. C., (1991).

Innovatory planning: antecipating social and technological innovation [Res]. Proceedings Of The Congrés International in France: Le Génie Industriel: facteur de Competitivité des enterprises, Tours, França, 3.
Melo, M.A. C. (2003).

Innovatory planning: methods and instruments. Proceedings of The International Conference of the Global Business and Technology Association, Budapest, Hungría, 7.

Melo, M. A. C., \&

Melo, L.C.P. (1985).

Os agentes reticuladores e o processo de planejamento: um estudo de caso. Anais do Simpósio Nacional de Pesquisa de Administração em $C \& T$, São Paulo, SP, Brasil, 10.

Miles, R. E., \&

Snow, C. C. (1986).

Organizations: new concepts for new forms. California Management Review, 28(3), 62-73.

Nohria, N. (1992).

Is network perspective a useful way of studying organizations? In $\mathrm{N}$. Nohria \& R.G. Eccles (Eds.). Networks and organizations: structure, form, and action. Boston, MA: Harvard Business School Press.

Piore, M. J., \&

Sabel, C. F. (1984).

The second industrial divide. New York: Basic Books.

Porter, M. (1998).

Clusters and the new economics of competition. Harvard Business Review, 76(6), 77-90.

Powell, W. W. (1990).

Neither market nor hierarchy: network forms of organizing. In B. Staw \& L.L. Cummings (Eds.). Research in organizational behavior. Greenwich, CT: JAI. 
Sheremetieff, A., Jr. (2003).

Redes organizacionais virtuais: caracterização, formação e gerenciamento. Dissertação de Mestrado, Pontifícia Universidade Católica do Rio de Janeiro, Rio de Janeiro, RJ, Brasil.

Smith, M., \&

Stacey, R. (1997, January).

Governance and co-operative networks: an adaptive systems perspective. Technological Forecasting and Social Change 54(1), 79-94.

Strauss, A.,

Schatzman, L.,

Ehrlich, D.,

Bucher, R., \&

Sabshin, M. (1963).

The hospital and its negotiated order. In E. Friedson (Org.). The hospital in modern society (pp. 147-169). Londres: The Free Press of Glencoe

Stringer, J. (1967).

Operational research of 'multiorganizations". Operational Research Quartely, 18(2), 105-120.
Trist, E. L. (1976, July 19).

A concept of organizational ecology [Paper based on an invited address to the Melbourne Universities: Department of Psychology (University of Melbourne), the Department of Sociology and Anthropology (Monash University) and the Department of Sociology (La Trobe University)]. USA.

\section{Trist, E. L. (1981).}

The evolution of socio-technical systems. A Conceptual Framework and an Action Research Program. Occasional paper (2). Ontario Quality of Working Life Centre, Toronto, Ontario, 1981.

\section{Uzzi, B. (1997, March).}

Social Structure and competition in interfirm networks: the paradox of embeddedness. Administrative Science Quarterly, 42(1), 37-69.

Uzzi, B. (1996, August).

The sources and consequences of embededness for the economic performance of organizations: the network effect. American Sociological Review, 61(4), 674-698. 